\title{
Organizational and pedagogical conditions for training higher education ap- plicants by learning tools of a competence-oriented environment
}

\author{
Ilona Batsurovska ${ }^{1, *}$, Nataliia Dotsenko ${ }^{1, * *}$, Olena Gorbenko ${ }^{1, * * *}$, and Nataliia Kim $^{1, * * * *}$ \\ ${ }^{1}$ Mykolayiv National Agrarian University, 9 Georgya Gongadze Str., Mykolayiv, 54020, Ukraine
}

\begin{abstract}
The organizational and pedagogical conditions for training higher education applicants by learning tools of a competence-oriented environment are analysed. Such pedagogical conditions include integration of the educational process in the context of the face-to-face training and a competence-oriented computer environment, providing systematic interactive work and performance of rating tasks in a learning environment focused on competence and systematic monitoring and control over the process of training of higher education applicants. In order to study the feasibility of using organizational and pedagogical conditions for the training of higher education applicants by learning tools of a competence-oriented environment, the degree of competence of the expert commission was checked and the indicators of competences of experts were calculated. Experimental work on determining the coefficient of concordance gives the opportunity to state that the opinions of experts on the organizational and pedagogical conditions for the training of higher education applicants by learning tools of a competence-oriented computer environment are consistent. It is noted that the implementation of organizational and pedagogical conditions, in fact, involves the optimization of educational and cognitive activities of higher education applicants, and taking into account certain conditions will lead to renewal, productivity, continuity and integrity of acquisition of the competences.
\end{abstract}

\section{Introduction}

Dynamic increase in the amount of knowledge to be acquired by the higher education applicant during the years of study at the higher education institution, increasing the requirements for his professional and special training necessitates, the urgent need for a comprehensive and deep study of the system, pedagogical methods, external and internal factors of formation of specialist regularities and features of vocational training and their use in the educational process. The understanding of events, facts, phenomena is changing rapidly, it requires to constantly monitor the information, which makes it impossible to immerse oneself in a specific problem during only the study time. To solve the problem of improving the quality of perception of educational material in higher education, organizational and pedagogical conditions are introduced, which include integration, regularity and monitoring of educational activities and as a result - the acquisition of competencies. Such conditions can contribute to the formation of important components of professional competence, as well as the achievement of two strategic goals - improving the efficiency of all types of educational activities and improving the quality of training higher education applicants in accordance with modern information society.

The relevance of the study of the problem is determined by a set of factors. First, the integration of the

\footnotetext{
*e-mail: batsurovska_ilona@outlook.com

**e-mail: dotsenkona@outlook.com

***e-mail: gorbenko_ea@mnau.edu.ua

****e-mail: kim_ni@mnau.edu.ua
}

learning process in the context of the face-to-face training of the higher education institution and the competenceoriented computer environment. At the stage of transformation processes in modern society, the processes of integration into the education system acquire national significance, it becomes a necessary condition for the growth of professionalism of the specialist. Secondly, the problem of providing systematic interactive work and performance of rating tasks in a competence-oriented computer environment is caused by the need to resolve socio-pedagogical contradictions between the needs of pedagogical science and the need to predict trends in the national education system, social demands of society for training specialists and real practice. Third, the objective need for systematic monitoring and control over the process of training is determined by the needs of development and analysis of trends in higher education. Optimally selected pedagogical conditions for the training higher education applicants contribute to the formation of the ability of the future specialist to work in modern conditions.

\section{Literature review}

The use of electronic resources in the educational process in higher education can contribute both to developing professional skills and gaining the experience of using online environment $[1,2]$. The features of influence on the configuration of computer-based environment of hardware and software ICT tools, decomposition of techniques of 
their use in educational process of educational institutions are considered [3].

The tendencies to the learning outcomes description are revealed on the basis of the European Digital Competence Framework 2.0 and Digital Competence Framework $2.1[4,5]$. Competency-based learning refers to systems of instruction, assessment, grading, and academic reporting that are based on students demonstrating that they have learned the knowledge and skills they are expected to learn as they progress through their education, its general goal is to ensure that students are acquiring the knowledge and skills that are deemed to be essential to success in school, higher education, careers, and adult life $[6,7]$.

The European Commission adopted Competences for Lifelong Learning [8]. Critical thinking, entrepreneurship, problem solving or digital competences are just some of the competences [9-12]. It is provided a valid and reliable instrument to measure teachers' digital competence on the basis of the European Framework for the Digital Competence of Educators (also referred to as DigCompEdu) and to examine the relation between in-service teachers' digital competence and personal and contextual factors $[13,14]$.

Learner-centered environments tended to show greater numbers of positive outcomes than did knowledgecentered environments [15]. Conditions of e-learning associated with institutional, developer, instructor, student and technology issues were identified [16]. The design of blended learning environments brings with it some challenges: incorporating flexibility, stimulating interaction, facilitating students' learning processes [17-21].

The issue of pedagogical conditions was investigated by researchers G. T. Karabalaeva, U. Z. Akmatova [22], E. V. Muravyova, S. G. Dobrotvorskaya and E. I. Alekseeva [23], A. Salavatova, E. Bauer and O. Istrofilova [24], O. Kovshar, M. Baditsa and K. Suiatynova [25].

The importance of development the pedagogical conditions for forming the information competence is noted [26]. The study examined the extent to which instructional conditions influence the prediction of academic success in the undergraduate courses offered in a blended learning model. The results suggest that it is imperative for learning analytics research to account for the diverse ways technology is adopted and applied in course-specific contexts [27].

A consistent transition between disciplines will contribute to the formation of a consistency of knowledge based on the development of general scientific ideas and concepts, the improvement of professionally oriented knowledge and skills of students [28]. Using ICT tools it is possible to overcome the challenges and to realize the acquisitions of the competences [7, 29-39].

The designing e-assessment processes aligned with competences and learning activities is useful for helping students attain the desired competence levels [40, 41]. There are revealed a set of cloud computing tools for certain collaborative learning activities categorized under sharing, editing, communication and discussion [42, 43].

The research trends were identified: theoretical foundations of multimedia learning, representations and princi- ples, instructional design and individual differences, motivation and metacognition, and video and hypermedia [44]. Analysing scientific and pedagogical sources and taking into account world experience, it can be argued that in order to achieve maximum results, higher education institutions need to use the organizational and pedagogical conditions that provide the development of the future specialist's professional competences.

The aim of the article is to theoretically substantiate and experimentally check the organizational and pedagogical conditions for the training of higher education applicants by learning tools of the competence-oriented environment.

\section{The method of determination of the competence of experts}

In order to check the expediency of using the organizational and pedagogical conditions, 15 experts were selected. To test the level of competence of the expert panel, we calculated the corresponding expert competence factor. As an important criterion for the selection of experts was their competence, during the evaluation we used the proposed method [45]. When selecting the experts, we took into account their pedagogical experience, the availability of printed works on certain problems and participation in activities aimed at improving the quality of training of higher education applicants in terms of a competenceoriented computer environment.

For the indicator that determines the length of service of an expert with higher education applicants $-K_{\text {ser }}$ (length of service) - the following values correspond:

- experience of work of an expert with higher education applicants up to 5 years - 0.3 ;

- experience of work of an expert with higher education applicants from 5 to 8 years -0.4 ;

- experience of work of an expert with higher education applicants from 8 to 12 years -0.5 ;

- experience of work of an expert with higher education applicants from 12 to 15 years -0.6 ;

- experience of work of an expert with higher education applicants from 15 to 20 years -0.7 .

The availability of printed works on problems related to the vocational training of higher education applicants and the introduction of massive online learning in higher education in Ukraine, is determined by the following values of the coefficient of publications $-K_{p . U A}$ :

- up to 5 publications are available -0.3 ;

- from 5 to 10 publications are available -0.4 ;

- from 10 to 20 publications are available -0.5 ;

- from 20 to 30 publications are available - 0.6;

- from 30 to 40 publications are available -0.7 .

The availability of printed works on problems related to the vocational training of higher education applicants 
and the problems of the introduction of a competenceoriented computer environment abroad in English ('publication rate'), denoted by the following values of the coefficient $\left(K_{p . \text { Eng. }}\right)$ :

- up to 5 publications are available -0.3 ;

- from 5 to 10 publications are available -0.4 ;

- from 10 to 20 publications are available -0.5 ;

- from 20 to 30 publications are available -0.6;

- from 30 to 40 publications are available - 0.7.

The availability of certificates certifying the completion of the course in a competence-oriented computer environment is indicated by the following coefficient values $\left(K_{\text {cer }}\right)$ :

- up to 3 certificates are available -0.3 ;

- from 3 to 5 certificates are available - 0.4;

- from 5 to 10 certificates are available -0.5 ;

- from 10 to 20 certificates are available - 0.6;

- more than 30 certificates are available - 0.7.

The presence of self-developed open online courses in a competence-oriented computer environment is indicated by the following coefficient values $\left(K_{\text {cour }}\right)$ :

- online course is available -0.3 ;

- from 2 to 4 online courses are available - 0.4;

- from 4 to 6 online courses are available -0.5 ;

- from 6 to 8 online courses are available - 0.6;

- more than 8 online courses are available - 0.7.

The degree of interest and competence of experts in the implementation of the competence-oriented computer environment in the vocational training of higher education applicants is determined by the following coefficient values $\left(K_{\text {exp. }}\right)$ :

- the expert has doubts about the implementation of training for higher education applicants in a competenceoriented computer environment -0.3 ;

- the expert shows interest in the introduction of a competence-oriented computer environment in the training of higher education applicants -0.4 ;

- the expert is pleased to introduce a competence-oriented computer environment in the training of higher education applicants -0.5 ;

- the expert has the theory and practice of introducing a competence-oriented computer environment into the training of higher education applicants -0.6 ;

- the expert has the skills and competencies to implement a competence-oriented computer environment in the training of higher education applicants -0.7 .

Given the value of the indicators, we determine the competence of each expert $K_{\text {com }}$ :

$$
K_{\text {com }}=\frac{K_{\text {ser }}+K_{p . U A}+K_{p . E n g .}+K_{c e r}+K_{\text {cour }}+K_{\text {exp. }}}{4.2}
$$

The maximum possible total coefficient of competence for the ideal expert can be calculated by the formula:

$$
\begin{array}{r}
K_{\text {ser }}+K_{p . U A}+K_{p . \text { Eng. }}+K_{\text {cer }}+K_{\text {cour }}+K_{\text {exp. }}= \\
=0.7+0.7+0.7+0.7+0.7+0.7=4.2
\end{array}
$$

For the ideal expert $K_{\text {com }}=1$.

The research methods also included analysis and synthesis of scientific, pedagogical, methodological sources and empirical methods, as well as analysis of the obtained results. Implementation of organizational and pedagogical conditions for training higher education applicants by learning tools of a competence-oriented environment is carried out on the basis of full-time and online learning. Before the introduction of organizational and pedagogical conditions and at the end of the experimental work, a study was conducted, which included an analysis of the quality of knowledge. The results obtained before and after the experiment were verified using the statistical criterion $\chi^{2}$ Pearson.

\section{Organizational and pedagogical conditions for training higher education applicants by learning tools of a competence-oriented environment}

Condition, in logic, is defined as a circumstances on which something depends; a set of rules that is established in a particular field of life; the situation in which something happens; these are the requirements to be repelled from [46]. The term 'pedagogical conditions' is defined as 'the circumstances on which the whole productive pedagogical process of professional training of professionals, mediated by the activity of the individual, by a group of people, depends' [47]. Their use in pedagogical practice contributes to the improvement of professional training include the organization and direction of the pedagogical process for the formation and development of professional readiness; application of personality-oriented approach and creation of personality-oriented relations; elimination of duplication of learning content by improving and maximizing the development of interdisciplinary links; use of virtual teaching methods with the use of information technology [48]. It is possible to define the pedagogical condition as external and internal circumstances, factors, a set of measures, factors that contribute to the successful course of a certain phenomenon; implementation of which aims to ensure a successful organizational, psychological and pedagogical, didactic support for the formation and development of the phenomenon under study.

The process of formation of pedagogical conditions is determined by the need to identify those aspects that contribute to the realization of the most important target settings of using the basic principles of vocational education as practical means for professional activity. In recent years, radical changes have occurred in the world of science. They have set new targets for the modernization of educational and e-learning environments based on a competence-oriented computer environment. 
The organisational and pedagogical conditions for training higher education applicants by learning tools of a competence-oriented environment include:

1) integration of the educational process in the context of the face-to-face training of a higher education institution and a competence-oriented computer environment;

2) providing systematic interactive work and performance of rating tasks in a computer environment focused on competence;

3) systematic monitoring and control over the process of training of higher education applicants.

Integration of the educational process in the terms of face-to-face training of a higher education institution and a competence-oriented computer environment is one of the most promising innovations that can solve the numerous problems of the modern education system. Of course, the system of integrated learning is not well developed, that's why it is perceived by many educators ambiguously. Its full theoretical substantiation and introduction into teaching practice is a matter of the future. Integration requires the use of a variety of forms of teaching, which has an impact on the effectiveness of higher education applicants' perception of studying material. The development of the idea of knowledge integration gives the opportunity to form qualitatively new knowledge of higher education applicants, characterized by higher level of thinking, dynamic application in new situations, increasing their effectiveness and systematic work. Systemic holistic knowledge is a state, a result that can be reached through integration [49].

The competence-oriented computer environment is seen as a new organization of the educational process, based on the principle of self-study of higher education applicants. To work in a competence-oriented computer environment, it is necessary to develop methodological and technological skills of higher education applicants and professors who carry out their training. Methodical skills require knowledge of disciplines using a competencebased computer environment and dealing with structured educational information content that can be presented in the form of interactive learning tools, such as interactive lectures, multimedia simulators, presentations, creative works, individual assignments, etc. is relevant [50]. Technological skills imply ability to work with technology, it is necessary to define rational limits of requirements for personnel who will work with this technology [51]; coordination and step-by-step implementation of actions and operations aimed at achieving the desired result; the uniqueness and the regularity of the procedures and operations available in the technology.

The educational process requires constant monitoring in order to correct its development in the right direction in time. For this purpose, monitoring is used. Monitoring is a system of continuous control of the development and performance of a holistic process, which is analysed by specially selected parameters and on the basis of accepted criteria [52]. Control, as a didactic concept, is a set of conscious actions aimed at obtaining information about the level of acquisition of higher education applicant, program material, mastering the theoretical and practical knowledge, skills and competences required in the process of performing tasks. Pedagogical control is a system of verification of the results of education and upbringing of higher education applicants [53]. Systematic monitoring and control over the process of training of higher education applicants in a competence-oriented computer environment will facilitate the intensity of their education and the acquisition of competencies in the specialty.

The implementation of the first condition was ensured through the study of disciplines in the context of face-toface training and online learning courses in a computer environment focused on competence. Preparation for the face-to-face class involved studying the material in an online course. Thus, face-to-face training was carried out with the help of modern educational technologies and took into account the results of work in online learning courses.

The implementation of the second condition - the provision of systematic interactive work and performance of rating tasks in a computer environment, focused on competence, was carried out with the help of the specified environment. Online courses included the study of interactive lectures with video elements, complex tasks, research papers, interactive seminars and various tests.

The implementation of the third condition - systematic monitoring and control over the process of training of higher education applicants - provided for systematic monitoring of the results of tasks in the online course and the degree of acquisition of competencies. Monitoring should be carried out in relation to the completed tasks, passing tests, attending the course, reviewing modules, performing control tasks.

\section{Results}

Factor analysis in pedagogy is based on the relevant section of mathematics, where the procedure of separation of factors for a variety of reasons (variables) is developed. Its task in pedagogy is, first, to develop ways of consistent selection of causes, secondly, to reveal the mechanism of constructing factors from them and, third, to investigate objectively these factors, to determine the contribution of each to the final product, to establish a hierarchy (subordination) between them [54]. As new knowledge is accumulated by means of factor analysis (table 1), it is possible to solve more complex problems: establishing inter-factorial relationships, clarifying areas and limits of pedagogical regularities. Thus, the table gives the opportunity to get the final value in percentage. The difference with the ideal indicator is calculated as a numerical value and the factor indicator is given as a percentage. That is, the final percentage value, which is represented in the table by linear histograms, gives us an idea of each expert's level of competence. The lowest figure is $57.16 \%$ and the highest is $83.34 \%$. The difference between the lowest competence indicator with an expert expert's competence score is $42.84 \%$ and the difference between the highest compe- 
Table 1. Factor analysis

\begin{tabular}{lllll}
\hline Expert & $\begin{array}{l}\text { Factor } \\
\text { indica- } \\
\text { tor }\end{array}$ & $\begin{array}{l}\text { Difference } \\
\text { with } \\
\text { ideal in- } \\
\text { dicator }\end{array}$ & $\begin{array}{l}\text { Factor } \\
\text { indi- } \\
\text { cator, } \\
\%\end{array}$ & $\begin{array}{l}\text { Resulting } \\
\text { value, } \\
\%\end{array}$ \\
\hline 1 & 2.6 & 1.6 & 38.08 & 61.92 \\
2 & 3.5 & 0.7 & 16.66 & 83.34 \\
3 & 3.3 & 0.9 & 21.42 & 78.58 \\
4 & 2.5 & 1.7 & 40.46 & 59.54 \\
5 & 2.9 & 1.3 & 30.94 & 69.06 \\
6 & 2.7 & 1.5 & 35.70 & 64.30 \\
7 & 2.8 & 1.4 & 33.32 & 66.68 \\
8 & 3.2 & 1.0 & 23.8 & 76.20 \\
9 & 2.9 & 1.3 & 30.94 & 69.06 \\
10 & 3.0 & 1.2 & 28.56 & 71.44 \\
11 & 2.6 & 1.6 & 38.08 & 61.92 \\
12 & 2.4 & 1.8 & 42.84 & 57.16 \\
13 & 3.1 & 1.1 & 26.18 & 73.82 \\
14 & 2.8 & 1.4 & 33.32 & 66.68 \\
15 & 2.7 & 1.5 & 35.70 & 64.30 \\
\hline
\end{tabular}

tence indicator with an expert expert's competence score is 16.66 .

For the ideal expert $K_{\text {emp. }}=1.2$, but for real experts $K_{\text {emp. }}$. will be less than 1 . The determination of the expert competence coefficient is presented in table 2 .

The representativeness of the expert group shows the arithmetic mean of the reliability of all experts and is formed by the formula:

$$
K_{p}=\frac{K_{k 1}+K_{k 2}+K_{k 1}+\ldots K_{k n}}{15}=0.683
$$

The expert group is considered representative if $K_{p} \geq 0.55$.

If $2 / 3$ of the experts satisfy the condition $0.55<K_{p}<1.0$, then the results of the peer review can be considered representative. Therefore, the expert group is composed of 15 experts with a representative index of 0.683 that meets the requirements. Therefore, the results of the peer review can be considered representative. Using the method of expert assessments, we will determine the consistency of experts' opinions on the expediency of using the organizational and pedagogical conditions of applying a competence-oriented computer environment in the vocational training of higher education applicants. Expert assessments depend on the number of experts. In this case, reducing their number exaggerates the role of each of them. It is believed that the optimal size of the expert group should be 15-20 specialists. In our case, 15 experts were selected. This statistical method allows you to evaluate the phenomenon under study in the form of a generalized opinion of experts on the issue or problem. The experts expressed their opinion in terms from 1 to 10 . We determined the degree of agreement of experts by the coherence of the coefficient of concordance $(W)$. We followed the following calculation procedure.

1. Filled in the summary table of thoughts.
2. The sum of the grades obtained by each higher education applicant was calculated: $\sum_{i=1}^{15} x_{i}$.

3. The arithmetic mean of the ranks was calculated: $X=\frac{1511}{25}=6044$.

4. The deviation of the sum of ranks of each indicator of the corresponding condition from the arithmetic mean sum of ranks was calculated.

5. 5. Square the deviation of the sum of the rank of each indicator of the corresponding condition, sum the obtained numbers and find $S=11234$.

6. Determine the coefficient of concordance by the formula:

$$
W=\frac{12 \cdot S}{m^{2} \cdot\left(n^{2}-n\right)}=\frac{12 \cdot 11234.16}{15^{2} \cdot\left(25^{2}-25\right)} \approx 0.038
$$

$m$ - the number of experts, $n-$ the number of indicators of the relevant conditions.

Depending on the degree of importance of the experts' opinions, the coefficient of concordance is in the range from 0 (in the total absence of agreement) to 1 (with absolute unanimous vote of experts). Thus, the experimental work done on determining the coefficient of concordance gives the opportunity to state that the opinions of experts regarding the expediency of using the conditions of training of higher education applicants with the use of a competence-oriented computer environment.

Before the introduction of the conditions developed by experts in the educational process, an experimental section of knowledge was conducted. 240 people took part in the experiment, of which 119 students were a control group, and 121 - an experimental group. Upon completion of the experimental work, the level of students' knowledge was also investigated using a control slice.

We present in the form of a table the results of experimental work. Thus, the levels of knowledge quality in the control (CG) and experimental (EG) groups are presented in tables 3 and 4 in the in the form of percentage and empirical values $\left(n_{i}\right.$ for the experimental and $n_{i 1}$ for the control group).

It is calculated the empirical value $\chi^{2}$ before and after the experiment in the control and experimental groups [54]. At the beginning of the experiment:

$$
\chi^{2}=\sum_{x=1}^{3} \frac{\left(n_{i}-n_{i 1}\right)^{2}}{n_{i 1}}=0.58
$$

At the end of the experiment:

$$
\chi^{2}=\sum_{x=1}^{3} \frac{\left(n_{i}-n_{i 1}\right)^{2}}{n_{i 1}}=54.97
$$

Taking into account the degree of freedom $v=2$ ( $v=k-1, k=3$ ), critical for $\chi^{2}$ for statistical levels $\rho \leq 0.05$ and $\rho \leq 0.01$. Thus, $5.991<\chi_{\text {crit }}^{2}<9.210$. The obtained empirical value of Pearson's $\chi^{2}$ before the experiment is less than critical. That is, $\chi_{e m p}^{2}<\chi_{c r i t}^{2}$, which 
Table 2. Determination of the competence of experts $K_{\text {exp. }}$.

\begin{tabular}{cllllllll}
\hline Expert & $K_{\text {ser }}$ & $K_{p . U A}$ & $K_{p . E n g .}$ & $K_{\text {cer }}$ & $K_{\text {cour }}$ & $K_{\text {exp. }}$ & Total & $K_{\text {com }}$ \\
\hline 1 & 0.4 & 0.5 & 0.3 & 0.5 & 0.4 & 0.5 & 2.6 & 0.619 \\
2 & 0.5 & 0.7 & 0.4 & 0.7 & 0.5 & 0.7 & 3.5 & 0.833 \\
3 & 0.7 & 0.5 & 0.4 & 0.5 & 0.7 & 0.5 & 3.3 & 0.786 \\
4 & 0.5 & 0.3 & 0.5 & 0.4 & 0.5 & 0.3 & 2.5 & 0.595 \\
5 & 0.5 & 0.4 & 0.7 & 0.4 & 0.5 & 0.4 & 2.9 & 0.690 \\
6 & 0.3 & 0.4 & 0.5 & 0.3 & 0.6 & 0.6 & 2.7 & 0.643 \\
7 & 0.5 & 0.4 & 0.5 & 0.4 & 0.5 & 0.5 & 2.8 & 0.667 \\
8 & 0.6 & 0.5 & 0.3 & 0.5 & 0.6 & 0.7 & 3.2 & 0.762 \\
9 & 0.5 & 0.4 & 0.5 & 0.7 & 0.3 & 0.5 & 2.9 & 0.690 \\
10 & 0.4 & 0.5 & 0.6 & 0.4 & 0.5 & 0.6 & 3.0 & 0.714 \\
\hline
\end{tabular}

Table 3. Levels of quality of students 'knowledge in control and experimental groups at the beginning of the experiment

\begin{tabular}{lllll}
\hline Level & $\mathrm{EG}, \%$ & $\mathrm{EG}, n_{i}$ & $\mathrm{CG}, \%$ & $\mathrm{CG}, n_{i 1}$ \\
\hline $\mathrm{A}$ & 7.14 & 8 & 6.42 & 7 \\
$\mathrm{BC}$ & 37.50 & 42 & 41.28 & 45 \\
$\mathrm{DE}$ & 63.39 & 71 & 61.47 & 67 \\
\hline Total & 108.04 & 121 & 109.17 & 119 \\
\hline
\end{tabular}

Table 4. Levels of quality of students 'knowledge in control and experimental groups at the end of the experiment

\begin{tabular}{lllll}
\hline Level & $\mathrm{EG}, \%$ & $\mathrm{EG}, n_{i}$ & $\mathrm{CG}, \%$ & $\mathrm{CG}, n_{i 1}$ \\
\hline $\mathrm{A}$ & 27.68 & 31 & 12.84 & 14 \\
$\mathrm{BC}$ & 63.39 & 71 & 44.95 & 49 \\
$\mathrm{DE}$ & 16.96 & 19 & 51.38 & 56 \\
\hline Total & 108.04 & 121 & 109.17 & 119 \\
\hline
\end{tabular}

means that they belong to the zone of insignificance, and therefore the levels of quality of students' knowledge in the control and experimental groups at the beginning of the experiment do not have significant differences.

The obtained empirical value of Pearson's $\chi^{2}$ at the end of the experiment is more than the critical $\chi_{e m p}^{2}>\chi_{\text {crit }}^{2}$, which means that they belong to the zone of significance, and therefore the levels of quality of students' knowledge in the control and experimental groups at the end of the experiment have significant differences. The proposed organizational and pedagogical conditions for training higher education applicants by learning tools of a competenceoriented environment improve the quality of the educational process. The result of their implementation is the mastery of professional disciplines and the acquisition of quality knowledge and competences.

\section{Conclusion}

Thus, the organizational and pedagogical conditions for the training of higher education applicants by learning tools of a competence-oriented environment are theoretically substantiated and experimentally checked. Such pedagogical conditions include integration of the educational process in the context of the face-to-face training and using the competence-oriented computer environment, providing systematic interactive work and performance of rating tasks in the competence-oriented environment focused on competence and systematic monitoring and control over the process of training of higher education applicants. The effective influence of higher education institutions on the improvement of the educational process is based on such organizational and pedagogical conditions. The implementation of organizational and pedagogical conditions, in fact, involves the optimization of educational and cognitive activities of the higher education applicants. Taking into account certain conditions will lead to a conductive learning environment and support for renewal, productivity, continuity and integrity of the acquisition of competencies.

Prospects for further research are related to the study of the specifics of monitoring activities in various areas of vocational education, as well as further improvement of the process of learning management in higher education in a combination of face-to-face and online learning.

The materials of the article can be used in the field of research of structural components of modern pedagogical processes in order to ensure their organic unity in the education system.

\section{References}

[1] M. Popel, S. Shokalyuk, M. Shyshkina, CEUR Workshop Proceedings 1844, 327 (2017)

[2] O. Stupak, Advanced Education 7, 97 (2020)

[3] O.M. Sokolyuk, Information Technologies and Learning Tools 23 (2011)

[4] O.O. Hrytsenchuk, I.V. Ivaniuk, O.Y. Kravchyna, I.D. Malytska, O.V. Ovcharuk, N.V. Soroko, Information Technologies and Learning Tools 65, 316 (2018)

[5] European e-Competence Framework, A common european framework for ict professionals in all sectors (2016), https://www . ecompetences.eu/ e-cf-3-0-download/

[6] European Commission, Council recommendation on key competences for lifelong learning (2014), https://www.edglossary.org/ competency-based-learning/

[7] K.V. Vlasenko, I.V. Lovianova, T.S. Armash, I.V. Sitak, D.A. Kovalenko, Journal of Physics: Conference Series (2021, in press) 
[8] Key competences for lifelong learning brochure (2019), https://ec.europa.eu/education/ node/738_ka

[9] A. Abdula, H. Baluta, N. Kozachenko, D. Kassim, CEUR Workshop Proceedings 2643, 306 (2020)

[10] Y. Modlo, S. Semerikov, R. Shajda, S. Tolmachev, O. Markova, P. Nechypurenko, T. Selivanova, CEUR Workshop Proceedings 2643, 500 (2020)

[11] S. Semerikov, A. Striuk, L. Striuk, M. Striuk, H. Shalatska, E3S Web of Conferences 166 (2020)

[12] O.A. Konoval, T.I. Turcot, A.O. Solomenko, Journal of Physics: Conference Series 1840, 012014 (2021)

[13] O. Kuzminska, M. Mazorchuk, N. Morze, V. Pavlenko, A. Prokhorov, CEUR Workshop Proceedings 2104, 366 (2018)

[14] M. Lucas, P. Bem-Haja, F. Siddiq, A. Moreira, C. Redecker, Computers \& Education 160, 104052 (2021)

[15] A. Gegenfurtner, Educational Research Review 6, $153(2011)$

[16] T.J. McGill, J.E. Klobas, S. Renzi, The Internet and Higher Education 22, 24 (2014)

[17] O. Markova, S. Semerikov, A. Striuk, H. Shalatska, P. Nechypurenko, V. Tron, CEUR Workshop Proceedings 2433, 499 (2019)

[18] O. Bondarenko, S. Mantulenko, A. Pikilnyak, CEUR Workshop Proceedings 2257, 182 (2018)

[19] O. Bondarenko, O. Pakhomova, W. Lewoniewski, CEUR Workshop Proceedings 2547, 13 (2020)

[20] K. Polhun, T. Kramarenko, M. Maloivan, A. Tomilina, Journal of Physics: Conference Series 1840, 012053 (2021)

[21] R. Boelens, B. De Wever, M. Voet, Educational Research Review 22, 1 (2017)

[22] G. Karabalaeva, U. Akmatova, The European Journal of Education and Applied Psychology pp. 11-15 (2020)

[23] E. Muravyova, S. Dobrotvorskaya, E. Alekseeva, Pedagogical Conditions For The Formation Of Risk Thinking, in The European Proceedings of Social and Behavioural Sciences (2020), pp. 738-744

[24] A. Salavatova, E. Bauer, O. Istrofilova, Pedagogical Conditions of Multicultural Education at the University, in Proceedings of the International Session on Factors of Regional Extensive Development (FRED 2019) (Atlantis Press, 2020/01), pp. 53-57, ISBN 978-94-6252-882-6, ISSN 2352-5428

[25] O. Kovshar, M. Baditsa, K. Suiatynova, International Journal of Engineering and Advanced Technology 9, 4556 (2019)

[26] A. Kamaleeva, O. Muller, E. Mityushchenko, SHS Web of Conferences 87, 00049 (2020)

[27] D. Gasevic, S. Dawson, T. Rogers, D. Gasevic, The Internet and Higher Education 28, 68-84 (2016)

[28] G. Tleuzhanova, O. Andreyeva, Z. Akhmadieva, Bulletin of the Karaganda University. Pedagogy series 100, 92-97 (2020)

[29] Z. Bakum, K. Morozova, Metallurgical and Mining Industry 7, 164 (2015)
[30] Y. Modlo, S. Semerikov, E. Shmeltzer, CEUR Workshop Proceedings 2257, 148 (2018)

[31] V. Morkun, S. Semerikov, N. Morkun, S. Hryshchenko, A. Kiv, CEUR Workshop Proceedings 2257, 198 (2018)

[32] P. Nechypurenko, V. Soloviev, CEUR Workshop Proceedings 2257, 1 (2018)

[33] V.V. Oliynik, O.M. Samoylenko, I.V. Batsurovs'ka, N.A. Dotsenko, Information Technologies and Learning Tools 68, 140 (2018)

[34] I. Kholoshyn, O. Bondarenko, O. Hanchuk, E. Shmeltser, CEUR Workshop Proceedings 2433, 403 (2019)

[35] K. Vlasenko, O. Chumak, I. Sitak, O. Chashechnikova, I. Lovianova, Espacios 40 (2019)

[36] Y. Kazhan, V. Hamaniuk, S. Amelina, R. Tarasenko, S. Tolmachev, CEUR Workshop Proceedings 2643, 392 (2020)

[37] M. Moiseienko, N. Moiseienko, I. Kohut, A. Kiv, CEUR Workshop Proceedings 2643, 60 (2020)

[38] S. Shokaliuk, Y. Bohunenko, I. Lovianova, M. Shyshkina, CEUR Workshop Proceedings 2643, 548 (2020)

[39] T. Vakaliuk, V. Kontsedailo, D. Antoniuk, O. Korotun, S. Semerikov, I. Mintii, CEUR Workshop Proceedings 2732, 808 (2020)

[40] A.E. Guerrero-Roldán, I. Noguera, The Internet and Higher Education 38, 36 (2018)

[41] H. Shalatska, O. Zotova-Sadylo, O. Makarenko, L. Dzevytska, CEUR Workshop Proceedings 2732 , 1172 (2020)

[42] H. Al-Samarraie, N. Saeed, Computers \& Education 124, 77 (2018)

[43] K. Vlasenko, O. Chumak, D. Bobyliev, I. Lovianova, I. Sitak, CEUR Workshop Proceedings 2740, 278 (2020)

[44] J. Li, P.D. Antonenko, J. Wang, Educational Research Review 28, 100282 (2019)

[45] P. Grigoriev, I. Vasilieva, Statystycheskye metody $v$ psykholohycheskykh yssledovanyiakh (Statistical Methods in Psychological Research) (Tyumen State University, Tyumen, 2018)

[46] A. Hornby, Oxford Advanced Learner's Dictionary of Current English (Oxford University Press, 2004)

[47] A. Semenov, Slovnyk - dovidnyk z profesiinoi pedahohiky (Vocabulary reference book for professional pedagogy) (Palmyra, Odesa, 2006)

[48] R. Benson, C. Brack, Online learning and assessment in higher education: A planning guide (Elsevier, 2010)

[49] C. McAvinia, Online learning and its users: lessons for higher education (Chandos Publishing, 2016)

[50] C. Pappas, 7 best practices for developing personalized elearning courses (2016), https://tinyurl. com/4ndk23my

[51] N. Sydorov, N. Sydorova, E. Sydorov, O. Cholyshkina, I. Batsurovska, Development of an approach to using a style in software engineer- 
ing, Vol. 4 (2019), http://journals.uran.ua/ eejet/article/view/175665

[52] D. Babenko, I. Batsurovska, N. Dotsenko, O. Gorbenko, I. Andriushchenko, N. Kim, Application of Monitoring of the Informational and Educational Environment in the Engineering Education System, in 2019 IEEE International Conference on Mod- ern Electrical and Energy Systems (MEES) (IEEE, 2019), pp. 442-445

[53] T. Seufert, Educational Research Review 24, 116 (2018)

[54] P.E. Greenwood, M.S. Nikulin, A guide to chisquared testing (John Wiley \& Sons, 1996) 